\title{
KONTINUITAS DAN PERUBAHAN MAKNA LAGU KEBANGSAAN INDONESIA RAYA
}

\author{
Wisnu Mintargo \\ Program Studi Seni Pertunjukkan dan Seni Rupa Sekolah Pascasarjana \\ Universitas Gadjah Mada \\ dan \\ Institut Seni Indonesia Surakarta \\ Email: wis_num@yahoo.com.sg \\ R.M. Soedarsono \\ Guru Besar Universitas Gadjah Mada \\ Victor Ganap \\ Guru Besar Institut Seni Indonesia Yogyakarta
}

\begin{abstract}
The main objective of this paper is to analyze function of "heroic" Indonesia songs related to the struggle for Indonesian independence ( from 1945 to 1949) from a historical perspective. Through this analysis it is hoped that the process of the past, particularly the history of music development in Indonesia and the background of the use of the "heroic"Indonesia songs, can be reconstructed. Important aspects of Indonesian songs, as this paper shows, include a constructive function for ceremonies and advice for development. The ceremonial character is shown in the song of "Indonesia Raya". the national anthem.
\end{abstract}

Key words: National anthem

\begin{abstract}
ABSTRAK
Objek utama dari tulisan ini adalah menganalisis fungsi dari lagu perjuangan Indonesia sehubungan dengan kemerdekaan Indonesia 1945- 1949 dilihat dari perspektif sejarah. Analisis ini diharapkan bahwa proses sejarah masa lalu dapat direkonstruksi, khususnya sejarah perkembangan music di Indonesia, latar belakang penggunaan lagu-lagu perjuangan Indonesia. Salah satu aspek terpenting dalam penulisan ini adalah fungsi dari lagu perjuangan Indonesia yang terbagi dalam satu bagian, terutama adalah fungsi konstruksi dari lagu untuk upacara meliputi saran dari pembangunan. Karakter seremonial ditampilkan dalam lagu "Indonesia Raya" yaitu lagu kebangsaan.
\end{abstract}

Kata Kunci: Lagu Kebangsaan. 


\section{PENGANTAR}

Lagu 'Indonesia Raya' asal mulanya lagu perjuangan yang kemudian diangkat menjadi lagu kebangsaan dan disebut pula sebagai musik fungsional. Fungsi bersifat upacara lebih ditonjolkan dari pada nilai estetisnya, dimaksudkan secara seremonial tidak selalu harus memenuhi persyaratan teknik komposisi musik yang sempurna seperti karya musik simponi. Ahli ilmu jiwa massa mengatakan bagaimana pun lemahnya lagu kebangsaan ditinjau dari komposisi musik, tetapi daya tariknya mampu membangkitkan semangat terutama makna yang terkandung dalam syair lagu itu (Soelaiman Yoesoep, 1979:52). Dalam konteks sejarah, perubahan, dan perkembangannya dari judul penulisan ini adanya upaya melihat sejarah Indonesia dari sudut pandang orang Indonesia dengan menekankan dinamika masyarakat, sehingga Indonesia bukanlah hanya ajang dari permainan kekuatan luar semata-mata, yaitu dikotomi dari oposisi antara terjajah dan penjajah sebagai pusat perhatian.

Sejarah mempunyai peranan yang penting karena dengan melihat ke masa lalu akan dapat membangun masa depan yang lebih baik (Kuntowijoyo, 1994:111). Pada kenyataannya, Indonesia dari masa kemerdekaannya hingga reformasi selalu terjadi konflik sosial. Suasana politik rezim di era kepemimpinan yang berubah-ubah adalah akibat warisan kolonialisme masih mempengaruhi kebebasan demokrasi yang belum sepenuhnya padam. Tulisan ini berusaha melakukan dekonstruksi dan rekonstruksi perlawanan kolonisasi, sejalan dengan perubahan fungsi lagu "Indonesia Raya' dari masa penjajahan hingga kemerdekaan. Pendapat teori perubahan sosial yang dikemukakan oleh Robert E. Park dengan mengikuti pandangan Spencer dan Durkheim bahwa perubahan sosial yang terjadi dalam kesenian juga akibat adanya perubahan dari masyarakatnya sesuai dengan kondisi saat itu (Soedarsono, 2001:69). Dalam hal ini terjadinya perubahan pada lagu 'Indonesia' disesuaikan dengan konteks perkembangannya dibentuk oleh panitia lagu kebangsaan 'Indonesia Raya' menjelang detik-detik proklamasi kemerdekaan sebagai simbol perlawanan sekaligus sarana upacara.

Di tengah terpuruk dan upaya untuk bangkit lagi, bangsa ini tidak akan pernah lupa dengan peringatan sekaligus perayaan tahunan hari kemerdekaannya. Salah satu ritual yang tidak boleh diabaikan adalah menyanyikan lagu 'Indonesia Raya' sebagai kesepakatan di bawah semangat Nasionalisme yang telah ditetapkan sebagai lagu Nasional. Terlepas dari makna lagu bagi anak bangsa saat ini, lagu tersebut menjadi saksi sejarah serta ikut melakukan dan membuktikan perjuangan kedaulatan negara tercinta dari masa ke masa hingga pergantian generasi. Tentu tidak terlalu penting apakah perjuangan mau dipahami sebagai sebuah spirit fisik-non fisik karena pada kenyataannya banyak efek penguatan mental dari hasil impresi konseptual seniman musik. Timbulnya semangat, cinta, ketaatan, kesetiaan terhadap bangsa, dan negara dalam berbagai bentuk hanya sebagian dari maksud penciptaan karya ini.

Akhirnya penulisan sejarah sangat tergantung kepada kondisi objektif, berupa tersedianya sumber dan kondisi subjektif. Dimaksudkan dari uraian mengenai model yang kiranya jelas, untuk meningkatkan pengetahuan sejarah dalam menentukan strategi yang tepat sesuai kondisi objektif dan subjektif, serta tujuan dari penulisannya (Kuntowijoyo, 1994). Sejak awal penelitian lagu 'Indonesia Raya' telah dilakukan sejumlah pengumpulan data kualitatif, sehingga penulisan ini berhasil dihimpun dari buku-buku sejarah, majalah, brosur, makalah seminar, pidato ilmiah, jurnal dan sumber-sumbar lain. Dalam menganalisis data kualitatif yang diperlukan adalah melakukan seleksi data sesuai kebutuhan. Kemudian dilakukan eksplanasi secara kritis terhadap imformasi yang berhasil dikumpulkan melalui sumber tertulis yang dapat dipercaya (Soedarsono, 2001). Setelah selesai maka dilakukan penulisan secara bertahap dimulai gerakan Budi Utomo dan Sumpah Pemuda, masa pendudukan 
Jepang dan revolusi Indonesia, di masa kemerdekaan, dan analisis ini dibahas agar menjadi pengetahuan yang bermanfaat.

\section{PEMBAHASAN}

\section{Angkatan Pemuda Perintis 1908-1942}

Perjalanan sejarah politik kebudayaan terlihat bahwa perkembangan musik nasional Indonesia masa kolonial Hindia Belanda 1908-1942 disebut periode dalam sejarah pergerakan, bersamaan berdirinya Budi Utomo yang berjuang disebut sebagai angkatan perintis kemerdekaan. Sikap patriotisme pertama kali dipelopori oleh kalangan terpelajar dr. Sutomo dan dr. Wahidin Sudirohusodo dengan organisasi Boedi Utomo (1908). Dilanjutkan para pemuda tahun 1920-an dengan berbagai perkumpulan seperti dr. Satiman Wiryosanjoyo dengan mendirikan Jong Java di Yogyakarta tahun 1915, Paguyuban Pansundan (1914), Jong Sumatranen Bond (1917), Jong Minahasa (1918), Jong Ambon (1920), Jong Timorsh Verbond (1921), Kaum Betawi (1923). Menyusul kemudian Jong Batak Bond, Jong Celebes, Jong Borneo, Sekar Rukun, Islamieten Bond. Perkumpulan itu cikal bakal perjuangan kedaerahan, setelah tahun 1926 meningkat ke arah persatuan pemuda Indonesia semakin kuat sebagai jiwa nasional.

Awal penelitian terciptanya lagu 'Indonesia Raya' dimulai dengan sikap patriot W.R. Supratman seorang nasionalis, wartawan, dan seniman yang tergugah hatinya, setelah membaca sebuah artikel dalam surat kabar Fajar Asia, artikel itu menyebutkan"siapayang dapatmenciptakan lagu Kebangsaan Indonesia Raya yang dapat membangkitkan semangat rakyat". Artikel yang semula dimuat dalam majalah Timboel terbit di Yogyakarta, kemudian dikutip oleh surat kabar Fajar Asia pimpinan $\mathrm{H}$. Agus Salim. Artikel itu dibaca Supratman dan mengilhaminya dalam mempersatukan pemuda Indonesia lewat lagu ciptaannya. Meskipun lagu 'Indonesia' ciptaannya telah disosialisasikan dan diperlihatkan kepada rekannya Sugondo Jayopuspito, A. Sigit Ketua Perhimpunan Pelajar Indonesia dan Monotutu dipastikan bahwa lagu itu memenuhi syarat sebagai sebuah kriteria lagu kebangsaan (Soebagijo,1985:49; Soesilo, 1996; dan Mintargo, 2001:76).

Penciptaan lagu kebangsaan dengan semangat patriotisme merupakan upaya menyampaikan pesan konstruktif melalui musik. Harus diakui bukanlah pekerjaan mudah menghasilkan serangkaian lirik penuh makna di sebaliknya dengan ilustrasi musik yang menyertainya. W.R. Supratman sebagai pemuda ikut mendorong semangat perjuagan lewat lagunya setelah melalui lobby yang cukup panjang dengan para pemuda (Ganap, 2009:17). Dengan diilhami cita-cita kebangkitan nasional Boedi Utomo 1908, pada tanggal 28 Oktober 1928 yang mengikrarkan sumpah pemuda, yaitu satu nusa, satu bangsa, dan satu bahasa. Kesempatan itu dipergunakan oleh Supratman memperkenalkan lagunya di dalam ruang peserta kongres pemuda di gedung Indonesische Club, Kramat 106 Jakarta. Betapa hebatnya lagu disambut peserta dan beliau menerima ucapan selamat dari rekan-rekannya.

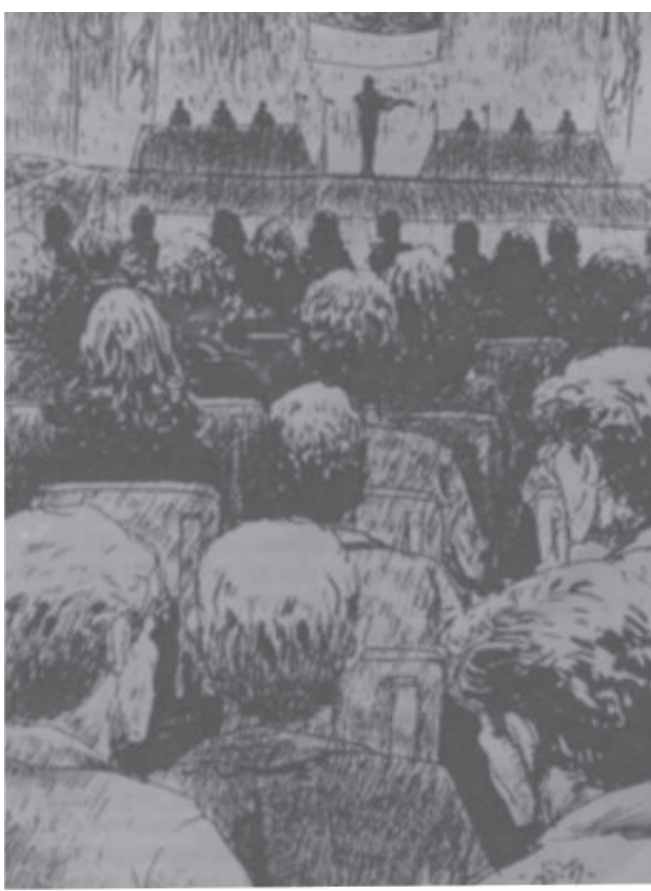

Gambar 1. W.R. Supratman dan Lagu 'Indonesia' di Gedung Kramat 106 Jakarta kongres Pemuda

28 Oktober 1928, rekonstruksi ilustrasi gambar Aji Soemarno P. 1982.(Sumber: Bambang Sularto Lagu Kebangsaan Indonesia Raya. Jakarta:Depdikbud, 1982, 62) 
Di lain pihak, Supratman memperoleh tudingan dari komponis pribumi karena memilih musik barat yang berakar dari Barat. Perlu dipahami bahwa konotasi Barat pada waktu itu sama artinya dengan kaum penjajah, sehingga lagu yang bernada Barat tentunya tidak layak disebut sebagai lagu kebangsaan. Selain memicu timbulnya konflik untuk merealisir gagasan ini, maka para empu gamelan tahun 1930-an sibuk memodernisir gamelan, dari segi praktek maupun teori agar musiknya dapat diterima etnis lain. Perubahan-perubahan dalam notasi musik diantaranya pernah ditulis dalam buku kecil Muhamad Yamin bahwa usaha-usaha memainkan lagu 'Indonesia' terbukti mengalami kegagalan karena secara teknis lagu itu memakai sistem tangga nada diatonis, sedang gamelan memakai sistem tangga nada pentatonik (Dungga dan Manik, 1952: 32).

Supratman memang tidak memasukan unsur, Melayu, Jawa, India, maupun Cina yang notabene menjadi simbol identitas kaum pribumi ketika itu tanpa alasan yang kuat. Namun diakuinya bahasa Melayu sebagai bahasa nasional sekaligus pemberlakuan musik diatonis sebagai musik nasional. Berikut transkripsi naskah teks asli lagu dan syair 'Indonesia' pada tahun 1928 yang diciptakan W.R. Supratman (Bambang Sularto, 1982:112).

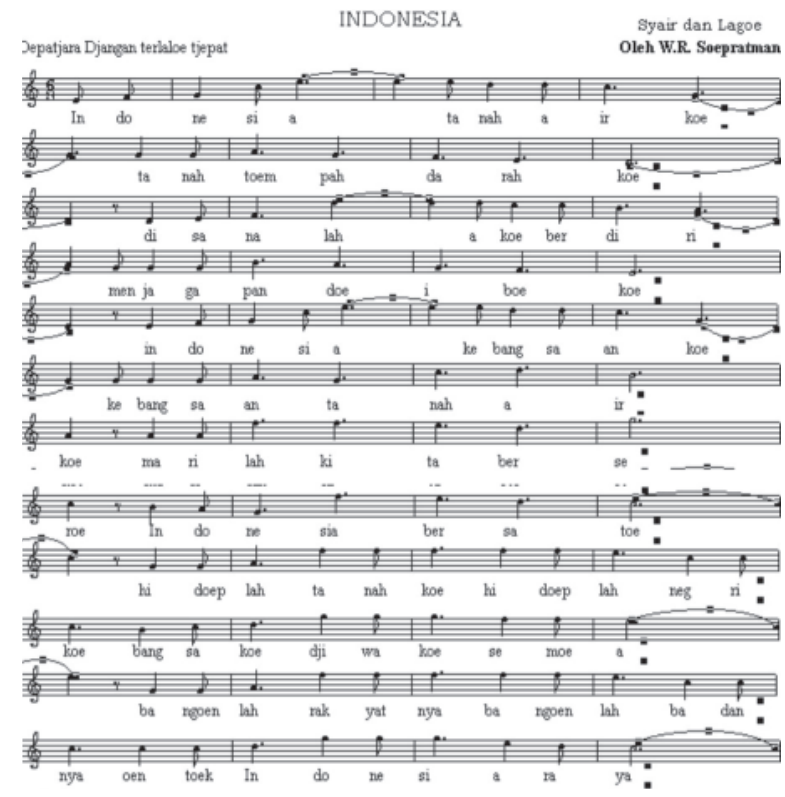

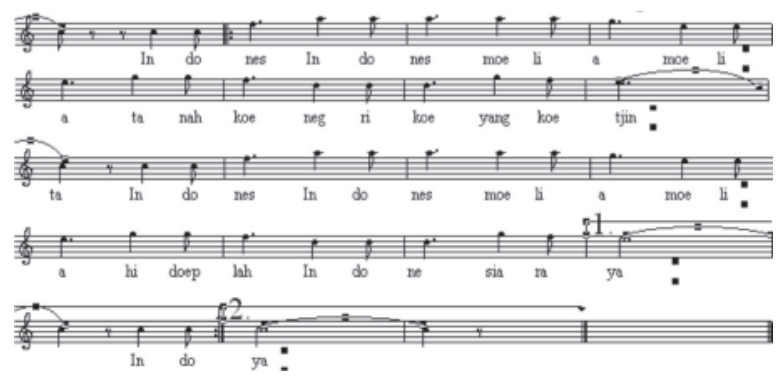

Berkumandangnya lagu 'Indonesia' awalnya dengan jumlah 81 birama ini memakai irama wals 6/8. Analisis lagu ini tidak memiliki tekanan yang kuat untuk menjadi irama mars, karena aksen yang datar dengan tempo lambat iringan musiknya dengan tangganada $C$ natural sesuai register instrumen biola dan belum memperhitungkan ambitus suara vokal manusia. Dalam kebanyakan musik terdapat jumlah ketukan-ketukan yang sama untuk setiap birama. Ketukan wals dihitung tiga ketukan (Triple) atau sukat susun 6 ketukan dalam satu birama. Resikonya lagu ini terasa lebih berat banyak memakai jumlah birama pada musiknya.

Lagu 'Indonesia' sebagai diplomasi awal memang peranannya sangat kuat untuk mempersatukan para pemuda diprediksi saat itu bangsa Indonesia belum berani terbuka dan berterus terang secara politis melawan penjajah, tentu sangat hati-hati dan tidak perlu memakai lagu bersifat mars. Lagu ini ditekan sedemikian termasuk strategi yang harus digunakan agar tidak menimbulkan kecurigaan pihak penguasa pemerintah Belanda, terutama makna dari syair yang terkandung misalnya syair Indones, indones, moelia, moelia pada klimaks lagu penciptanya memilih kata-kata yang halus, tetapi dapat juga memberi penguatan mental dan mampu membangkitkan semangat pemuda kala itu untuk bersatu.

Daya tarik tersebut akhirnya kaum pergerakan mempelajari lagu ini secara diam-diam, apabila belum memiliki notasi syairnya, dengan kesadaran mereka meminjam kepada teman kemudian disalin dan dihafalkan. Adakalanya pemuda menyanyikannya disaat bekerja atau 
sedang beristirahat. Penyebarluasan lagu di masa kolonial Hindia Belanda, bukan saja dilakukan oleh organisasi politik, tetapi juga pers dan dunia dagang. Perusahan piringan hitam produksi Yokimcan berhasil merekam lagu 'Indonesia' di luar negeri, tetapi karena ada larangan pemerintah Belanda akhirnya sebuah piringan hitam berhasil diselundupkan ke Indonesia. Harian Soeloeh pada tanggal 7 Nopember 1928 memuat teks lagu 'Indonesia' Sinpo dalam edisi majalah mingguan bulan Nopember 1928 juga memuat teks lagu ini. Supratman ikut berperan menyebarluaskan lagunya dengan melatih para pelajar, serta membagikan selebaran pamflet lagu ke masyarakat (Mintargo, 2008:30). Ilmu pengetahuan musik yang dimiliki W.R. Supratman diperoleh secara otodidak dan non-formal. Ilmu itu tidak dia dapatkan dari lembaga pendidikan formal, melainkan proses pembelajaran individual dari pemusik Barat, makanya dia lebih dikenal sebagai seorang nasionalis sejati.

Seiring keberadaan lagu itu, perjuangan diplomasi terus dilakukan oleh para tokoh pergerakan berbagai etnis di antaranya Sukarjo Wiryopranoto di Dewan Rakyat Hindia Belanda (Volksraad) mengusulkan, lagu 'Indonesia' diakui di samping lagu kebangsaan 'Wilelmus'. Sukardjo Wiryopranoto tokoh pergerakan nasional, memperjuangkanlaguagardiakuipemerintah Belanda. M.H. Thamrin tokoh Betawi ikut memperjuangkan lagu 'Indonesia' agar dapat diterima oleh pemerintah Belanda. Pidatonya tanggal 11 Juli 1939 di Volksraad, M.H. Thamrin mengecam pemerintah Belanda bersikap merendahkan Indonesia. Hamkah Seorang ulama Islam dari Sumatera Barat mengatakan, lagu 'Indonesia' telah diterima oleh seluruh rakyat Indonesia, sudah sewajarnya Belanda mengakui lagu itu sebagai lagu Kebangsaan Indonesia (Sutrisno, 1978:70). Di lain pihak, pengakuan itu telah membuat pemerintah kolonialisme melarang istilah kebangsaan. Jonkheer de
Graeff, Gubernur Jenderal Hindia Belanda dengan sinis mengatakan bahwa lagu 'Indonesia' tidak lebih dari lagu clublied atau lagu sebuah perkumpulan (Ganap, 2009).

Dari uraian di atas, maka pertama dapat dianalisis fungsi lagu 'Indonesia' kala itu, untuk mempersatukan para pemuda berlatar belakang berbagai etnis disebut sebagai perintis kemerdekaan. Oleh karena itu, lebih akurat dan netral hanya lewat musik diatonis pilihan satu-satunya sebagai alat perjuangan. Pengakuan bahasa melayu sebagai bahasa persatuan akibatnya kedudukan bahasa nasional menjadi alat komunikasi terpenting dalam berdiplomasi melawan penjajah termasuk teks syair lagu yang terkandung di dalamnya. Bahasa Indonesia sebagai alat komunikasi merupakan pemersatu berbagai etnis yang berbeda-beda merupakan kekalahan bagi bahasa Belanda yang diberlakukan sebagai bahasa pengantar sejak kongres pemuda pertama tahun 1926. Kedua fungsi lagu 'Indonesia' diakui sebagai jati diri bangsa menjadi perdebatan yang hangat di kalangan kaum intelektual pribumi. Polemik kebudayaan yang terjadi sekitar tahun 1930-an antara kelompok yang berpikiran nasionalis tradisional dan kelompok ultranasionalis merupakan fakta yang penting guna digarisbawahi. Polemik menunjukan komitmen kaum intelektual pribumi terhadap masa depan bangsa Indonesia. Kelompok nasionalis tradisional dengan tokohnya Ki Hadjar Dewantara dan Ali Boediardjo menginginkan jati diri bangsa Indonesia dibangun di atas nasionalisme yang tetap berakar pada budaya tradisi yang telah diwariskan oleh para leluhur bangsa. Sebaliknya kelompok ultranasionalis yang dipelopori oleh Sutan Takdir Alisjahbana dan Armijn Pane menghendaki sebuah wacana Indonesia baru yang dibangun di atas reruntuhan budaya lokal. Pemikiran tentang Jati diri bangsa Indonesia di masa depan hendaknya merupakan sebuah diskontinunitas sejarah, dengan mengubur dalam-dalam Chuvinisme etnisitas beserta simbol-simbol budaya lokalnya. 


\section{Pendudukan Jepang dan Revolusi 1945-1949.}

Masa pendudukan bala tentara Jepang, pemuda Indonesia disebut sebagai angkatan pendobrak menuju kemerdekaan. Pada awalnya dipicu musik propaganda Jepang menjelang pendaratannya di bumi Indonesia awal bulan maret 1942. Dimulai dengan siaran radio yang dipancarkan dari Tokyo dan radio pusat Jakarta dengan mengumandangkan lagu 'Indonesia Raya' untuk membangkitkan harapan rakyat. Pada tanggal 29 April 1942 Jepang bekerja sama dengan pemimpin Indonesia membentuk negara kesatuan Asia Timur Raya disebut tiga A, yaitu Nippon pemimpin Asia, Nippon pelindung Asia, dan Nippon cahaya Asia (Kamajaya, 1979:9).

Menurut Institute of Propaganda Analisys bahwa propaganda berasal dari bahasa latin propagare, berarti menyebarluaskan, yaitu suatu pengungkapan opini dari seseorang atau sekelompok massa dengan sengaja untuk mempengaruhi opini publik. Dalam arti yang lunak, propaganda menyiarkan keterangan, bermaksud menarik simpati masyarakat umum untuk tujuan kekuasaan (More, 1988:63).

Di masa pendudukan Jepang harapan ingin merdeka akan terwujud, pemerintah tidak melarang lagu 'Indonesia Raya' bahkan berguna bagi alat propaganda. Peranan lagu menjadi penting misalnya radio Tokyo, selalu membuka siarannya dengan semangat diiringi orkes simponi NHK Jepang yang di arransir dan di orkestrasi Nobuo Lida, tujuannya agar dapat mengambil hati dan simpati rakyat Indonesia. Propaganda Jepang kali ini berhasil menjalankan misinya secara halus, seolah-olah Jepang bagian dari bangsa kita. Saat rakyat bersemangat menjaga keamanan menyelenggarakan pemerintahan, Perdana menteri Tojo Hideki secara sepihak telah melarang lagu 'Indonesia Raya' serta pengibaran Sang Saka Merah Putih. Tanggal 29 April 1942 Jepang membuat undangundang baru nomor 4 menetapkan lagu 'Kimigayo' sebagai lagu wajib di negara jajahannya, bendera Himomaru wajib dikibarkan (Mintargo, 2002: 107).
Sejak saat itu keberadaan lagu 'Indonesia Raya' mengalami pasang surut dan tidak terdengar lagi di depan umum karena ketatnya pengawasan. Pada tahun 1944 Jepang mulai mengalami kekalahan dalam perang dunia ke II, posisinya mulai terdesak dan memerlukan bantuan Indonesia, barulah lagu itu diakui dan boleh diperdengarkan secara umum. Persiapan menyambut kemerdekaan tahun 1944, lagu 'Indonesia Raya' mengalami perubahan syair dan cara menyanyikannya. Untuk itu panitia lagu Kebangsaan pimpinan Sukarno dengan anggotanya Ki Hadjar Dewantara, Achyar, Bintang Sudibyo, Darma Wijaya, Kusbini, K.H. Mansyur, Mr. Muhammad Yamin, Mr. Sastro Moelyono, Sanusi Pane, Cornel Simandjuntak, Mr. Achmad Soebardjo, dan Utoyo. Setelah disahkan tahun 1944, lagu berkumandang dalam rapat pertemuan dan upacara tertentu (Sularto, 1982: 176).

Proses waktu yang panjang untuk lagu berjudul 'Indonesia' tahun 1928 kemudian pada tahun 1944 diubah menjadi lagu Kebangsaan 'Indonesia Raya' disebabkan Jepang tidak siap mengembalikan kekuasaan politik kepada pemerintah Indonesia. Perubahan itu meliputi teori musik dan tata bahasa dengan jumlah 41 birama mengutamakan penyederhanaan lagu agar lebih mudah dinyanyikan dan mengubah separoh penggunaan jumlah birama dari lagu aslinya. Pergantian birama 6/8 irama wals (Triple) dengan tempo Djangan Terlaloe Tjepat, diubah menjadi birama 4/4 marcia (Quardruple) hingga aksentuasi lagu semakin kuat dan tegas, sebab ketukan-ketukan mars empat ketukan dalam satu birama dengan tangga nada $G$ untuk ambitus suara manusia sudah dinilai tepat, baik vokal maupun instrumen musik pengiring. Kata 'mulya' yang kurang membangkitkan semangat diganti syairnya oleh aspirasi para pemuda menjadi kata 'merdeka'. Perubahan lagu disesuaikan perkembangan zaman sebagai sarana upacara. Lagu yang direvisi oleh panitia, tetap mempertahankan struktur lagu dan pesan semangat masih tetap murni ciptaan W.R. Supratman. 
Penelusuran sejarah ini berusaha memberikan gambaran yang utuh dengan cara paralelisasi fakta yaitu membandingkan antara lagu 'Indonesia Raya' tahun 1928 dengan perubahannya pada masa revolusi, sehingga data yang ditemukan ada kaitannya. Dalam hal ini kedudukkan sejarah kesenian dapat digambarkan melalui tulisan sejarah sebagai sebuah integrated equivalent menyuguhkan pemandangan menyeluruh (Kuntowijoyo, 1994:115). Semua dapat diamati dari perubahan teori musik, notasi, birama, irama, dan cara menyanyikannya. Perubahan dimaksudkan adalah sebagai ide baru disesuaikan dengan fungsinya mengikuti kriteria lagu kebangsaan yang bersifat semangat negara yang telah memenangkan peperangan, seperti Inggris, Rusia, dan Amerika.

Penelitian sejarah pergerakan revolusi dalam sosiologi dapat terungkap akibat benturan proses sosial dan perubahan sosial yang terjadi, akibatnya berdampak luas terhadap kehidupan bangsa. Revolusi salah satu penyebab terjadinya perubahan ketatanegaraan secara mendasar menyangkut perubahan politik, struktur sosial, ekonomi dan sikap budaya masyarakat. Revolusi diawali dengan pemberontakan dan kesenian dapat berfungsi sebagai media ekspresi (Marbun, 1996:557).

Dalam hal ini pandangan filsafat Difthey bersifat esensial historis bahwa peristiwa revolusi menunjukan jiwa manusia dalam keadaan tidak stabil kehidupan tidak pernah menentu dan mengalami perubahan karena pengaruh situasi yang sangat dasyat dan menekan di saat itu, sehingga manusia mengambil jalan pintas. Analisis hermeunetik dapat dibuktikan melalui intrepretsi dari syair lagu nasional sebagai nilai perjuangan merupakan alat diplomasi perlawanan (Sumaryono, 1996: 50). Sejarah pergerakan seperti dikemukakan Brosnilaw Malinowski di dalam teori fungsional, jika pada masa perang kemerdekaan tokoh pergerakan berusaha menyadarkan rakyat melalui pidato dan tulisan opini politiknya, pejuang dengan fisik dan strategi tempurnya digaris depan, maka seniman berjuang digaris belakang dengan memberi semangat dengan lagu ciptaannya (Yudistira, 1966:55).

Telah dikemukakan bahwa proses sebuah lagu perjuangan yang diubah statusnya menjadi lagu kebangsaan dalam upaya mempersatukan bangsa karena penjajahan sebagai penyebab kesengsaraan rakyat yang memicu timbulnya konflik sosial akibat krisis politik, ekonomi, dan kebudayaan sehingga ada beberapa faktor yang memicu yaitu: (1) kehilangan harga diri suatu bangsa, karena dijajah bangsa lain; (2) kehilangan harta benda, sanak saudara, hasil bumi oleh sewenang-wenang kaum penjajah; (3) kehilangan rasa adil akibat hakhak kemanusiaan dirampas oleh penguasa kaum penjajah; (4) kehilangan suatu kebebasan hidup di tanah airnya sendiri. Sebaliknya, sebagai perlawanan jati diri bangsa diwujudkan lewat simbol Bhinneka Tunggal Ika lagu kebangsaan 'Indonesia Raya' bagaikan Sang Saka Merah Putih yang polos dan sederhana berkibar dalam hati setiap insan Indonesia.

Menurut hukum internasional lagu kebangsaan hanya dimiliki oleh suatu negara yang merdeka. Walaupun status lagu kebangsaa 'Indonesia Raya' belum diakui sebagai lagu kebangsaan di forum internasional, tetapi secara tersirat sifat semangat kemerdekaan bangsa sudah nampak dalam lagu kebangsaan 'Indonesia Raya (Dewantara, 1948: 58). Selain itu dengan diperdengarkan lagu, ada tanda bahwa Indonesia masih memiliki harapan untuk bangkit dari keadaan pesimis menjadi optimis meraih kemerdekaannya. Setelah dicermati secara keseluruhan lagu kebangsaan 'Indonesia Raya', bait pertama, kedua, ketiga, dan bait keempat, makna yang terkandung di dalam lagu itu bersifat konstruktif dalam membangun bangsa. Unsur semangat terkandung dalam lagu dipengaruhi irama musik mars bersifat magnetic song bila lagu berkumandang, peserta upacara menjaga tata tertib berdiri di tempat penuh perhatian, hingga setiap orang mampu menghayati lagu dan sadar sebagai 
bangsa yang merdeka dan bersatu. Daya tariknya seperti magnit dan tidak jarang ikut mencucurkan air mata karena keagungan lagu itu. Pada akhirnya tanggal 17 Agustus 1945 dalam pembacaan teks proklamasi oleh Sukarno, di hadapan para pemimpin dan ratusan rakyat yang berkumpul pada pagi hari di jalan Pegangsaan timur, Jakarta, menyatakan kemerdekaan Indonesia. Setelah pembacaan teks proklamasi, pengibaran Sang Saka Merah Putih dilakukan, dengan serempak para hadirin menyanyikan lagu kebangsaan 'Indonesia Raya'. Peristiwa bersejarah itu tetap berlangsung hingga kini dan diperingati setiap tahun.

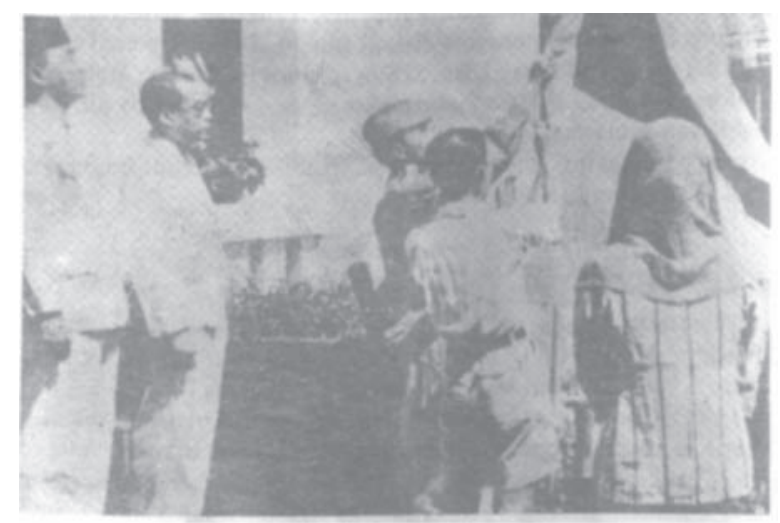

Gambar 2. Upacara 17 Agustus 1945 di Pegangsaan timur 56 Jakarta.

(Sumber: Radik Utoyo Sudirdjo, Lima tahun Perang Kemerdekaan 1945-1949. Jakarta: Penerbit Alda 1976, hal. 34.)

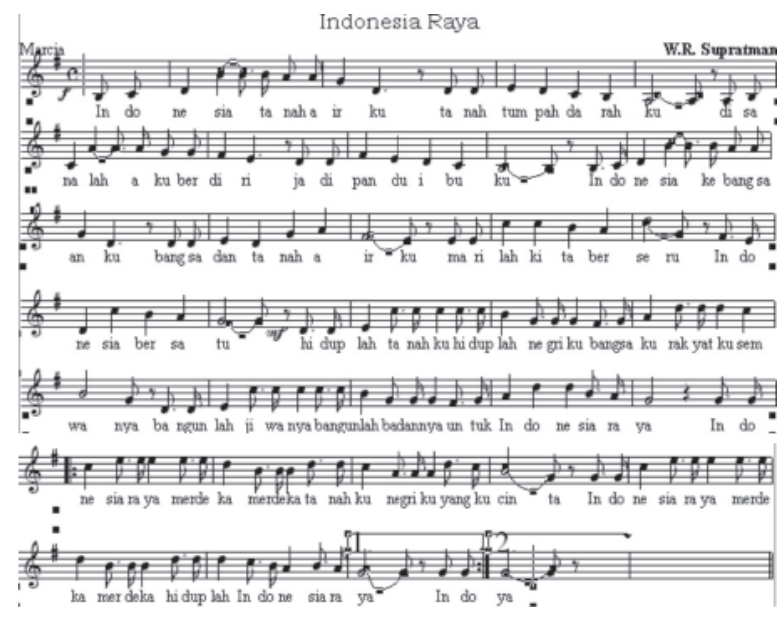

Pada tahun 1945 Jepang mengalami kekalahan perang akibat bom atom Sekutu. Belanda kembali membonceng Sekutu menancapkan kekuasaannya di Indonesia, rakyat menolak, dan mengadakan perlawanan fisik. Menurut James C. Dibdin bahwa analisis secara historis karakter suatu bangsa dapat dianalisa melalui sikap serta pemikiran nasionalnya, yaitu: (1) karakter bangsa yang mempunyai sifat pendendam dan kejam dalam peperangan; (2) karakter bangsa yang mempunyai sifat pemalas dan enggan berusaha; (3) karakter bangsa yang mempunyai sifat kesatria bila berjuang menghadapi tantangan dan penindasan. Sikap patriotisme dan pemikiran nasional pada bagian akhir inilah yang dimiliki oleh bangsa kita dengan berjuang mempersatukan bangsa dengan merebut kemerdekaan. Setelah bala tentara Jepang meninggalkan kekuasaannya, pemerintah Republik Indonesia mengambil alih kekuasaan. Pada tahun 1947 Ki Hadjar Dewantara dalam permusyawaratan pendidikan menetapkan bahwa upacara pengibaran sangsaka merah putih dan menyanyikan lagu kebangsaan 'Indonesia Raya' wajib diperdengarkankan setiap hari di halaman sekolah. Pemerintah menghentikan pengibaran bendera Jepang, menghapuskan lagu 'Kimigayo', meniadakan upacara dan pelajaran bahasa Jepang dengan mengganti semangat kebangsaan melalui pendidikan nasional, serta siap secara diplomasi menghadapi kaum penjajah Belanda dan sekutunya kembali ke bumi pertiwi.

Pada tanggal 19 Desember 1948 usaha diplomasi pemimpin pergerakan melalui markas PBB New York ditetapkan bahwa lagu kebangsaan yang diperjuangkan oleh bangsa Indonesia dicantumkan dalam negara RIS UUDS pasal 3 ayat 2 yang berbunyi bahwa lagu kebangsaan 'Indonesia Raya' ialah 'Indonesia Raya' Pada konferensi internasional yang diselenggarakan tanggal 29 Agustus 1949 di Jakarta, dihadiri oleh pemerintah Indonesia dengan pemerintah Belanda, yang diikuti pula oleh Belgia (ditunjuk Belanda), Australia (ditunjuk 
Indonesia). Amerika Serikat menekan Belanda agar mengakui eksistensi Indonesia. Dalam konferensi itu diputuskan: (1) Bendera Republik Indonesia Serikat (RIS) adalah Sang Saka Merah Putih; (2) Bahasa resmi RIS ialah Bahasa Indonesia; (3) Lagu kebangsaan RIS ialah 'Indonesia Raya'. Pada tanggal 27 Desember 1949, bertempat di Istana Gambir, Jakarta diadakan acara penurunan bendera Belanda dan pengibaran bendera Indonesia dalam rangka pengakuan secara simbolis kedaulatan Indonesia oleh Belanda. Acara dihadiri oleh A.H.J Loving sebagai komisaris tertinggi Belanda di Indonesia dan Menteri Pertahanan Sri Sultan Hamengkubuwono IX mewakili pemerintah Indonesia.

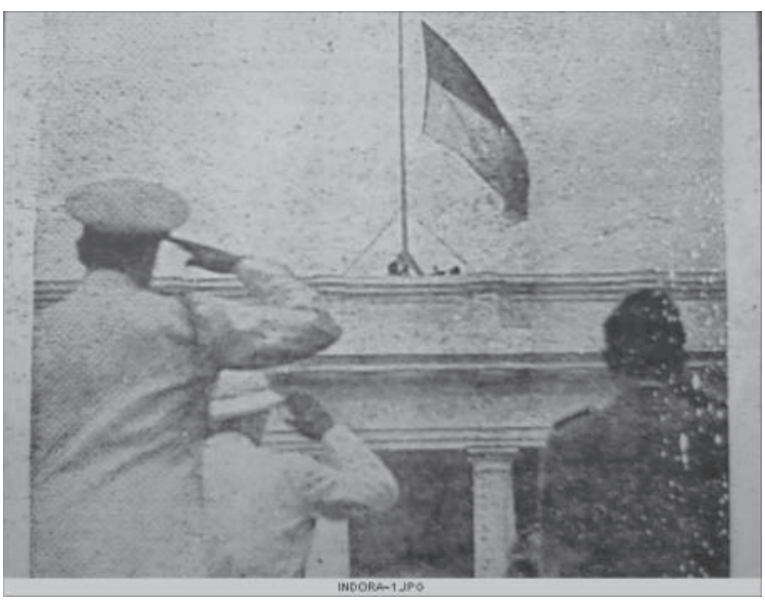

Gambar 3. Penyerahan Kedaulatan R.I dari Pemerintah Belanda kepangkuan Ibu Pertiwi tanggal 27 Desember 1949 di Istana Gambir Jakarta.(Sumber Soedrago, "Pemandangan

Dalam Negara" dalam Majalah Mimbar Indonesia, edisi 1 Jakarta 17 Januari 1950, hal. 5)

Upacara penyerahan dan penandatanganan kesepakatan disaksikan 22 wakil utusan PBB. Setelah penurunan bendera Belanda digantikan Sang Saka Merah Putih, maka berkumandanglah lagu Kebangsaan 'Indonesia Raya' tanda berakhirnya kolonialisme di Indonesia (Sudargo: 1950).

Dari uraian di atas dapat dianalisis pertama adalah fungsi lagu 'Indonesia Raya' sebagai alat propaganda oleh karena usaha-usaha Jepang memanfaatkan pemimpin Indonesia yang dimaksudkan agar pengaruh dan keinginannya berkuasa di Indonesia dapat bertahan lama seperti kolonial Belanda. Selain itu Jepang telah menabur janji kebencian terhadap bangsa lain dengan faham fasisme, baik secara halus maupun dengan jalan kekerasan agar bangsa Indonesia mau menerima begitu saja tanpa memikirkan akibatnya, seperti mengajak rakyat Indonesia melawan Amerika dan sekutunya. Diperdengarkan lagu kebangsaan 'Indonesia Raya' terbukti bahwa Jepang telah melancarkan propaganda terselubung secara halus guna menarik simpatik bangsa Indonesia. Akibatnya Indonesia terkecoh oleh janji-janji Jepang dan menerima kerugian besar bagi rakyat Indonesia.

Kedua Fungsi lagu sebagai sarana upacara kemerdekaan adalah menjadi citacita proklamator dan segenap seluruh rakyat Indonesia. Menurut Sukarno di depan sidang BPUPKI, kemerdekaan adalah jembatan emas, di seberangnya jembatan itulah kita bina seluruh rakyat Indonesia. Mengenai arti kemerdekaan terjadinya perubahan mendasar ketatanegaraan artinya dimulai sejak tanggal 17 Agustus 1945 bangsa Indonesia bebas dari penjajahan karena kemerdekaan adalah hak segala bangsa dan bebas tidak terikat oleh pihak manapun, termasuk dalam mengemukakan pendapat dan perlawanan terhadap kolonialisme.

\section{Pascakemerdekaan Kontra Reformasi}

Sudah saatnya di berlakukan reformasi secara menyeluruh terhadap ketetapan Pemerintah Nomor. 1 tanggal 17 Agustus 1959 menyatakan bahwa lagu kebangsaan 'Indonesia Raya' wajib dihormati, dihayati, dan diajarkan secara sungguh-sungguh dalam pendidikan moral kebangsaan guna membangun jati diri bangsa. Analisis makna yang terkandung dalam lagu kebangsaan 'Indonesia Raya' terjabar dalam syair sebagai berikut.

Bait I.

Indonesia Tanah airku Indonesia bersatu Tanah tumpah darahku Hiduplah tanahku Disanalah aku berdiri Hiduplah negriku 
Jadi pandu ibuku

Indonesia kebangsaanku

Bangsa dan tanah airku

Marilah kita berseru
Bangsaku, rakyatku, semuanya

Bangunlah jiwanya

Bangunlah badannya

Untuk Indonesia

Raya (kebait IV)

Bait IV.

Indonesia Raya, merdeka, merdeka

Tanahku, negriku yang kucinta

Indonesia Raya, merdeka, merdeka

Hiduplah Indonesia Raya

Bait II.

Indonesia tanah yang mulya Indonesia bahagia

Tanah kita yang kaya

Disanalah kita berada

Untuk slama-slamanya

Suburlah tanahnya

Suburlah jiwanya

Bangsanya,

rakyatnya,

semuanya

Indonesia tanah pusaka Sabarlah hatinya

P'saka kita semuanya Sadarlah budinya

Marilah kita mendoa Untuk Indonesia

Raya (kebait IV)

Bait III.

Indonesia tanah yang suci Indonesia abadi

Tanah kita yang sakti Slamatlah

rakyatnya

Disanalah aku berdiri Slamatlah

putranya

Jadi ibu sejati

Pulaunya, lautnya, semuanya

Indonesia tanah berseri Majulah negrinya

Tanah yang akau sayangi Majulah pulaunya

Marilah kita berjanji Untuk Indonesia

Raya (Kebait IV)

Bait pertama mengungkapkan hubungan yang sangat erat antarmanusia dengan lingkungan alam Indonesia. Begitu erat hubungan tersebut, sehingga lingkungan itu disebut sebagai tanah air, tanah tumpah darah, dan sebagai ibu pertiwi. Kebudayaan telah menempatkan hubungan antara manusia dengan lingkungannya, sehingga alam menjadi bagian dari hidupnya,

bagian dari sejarahnya, bagian dari proses kebudayaan. Pengertian kalimat itu, maka bangsa Indonesia menjadi satu definisi diri manusia sebagai subjek budaya, artinya bangsa Indoesia sebagai potensi manusianya, tanah air Indonesia sebagai lingkungan alamnya. Dalam bait pertama ditegaskan, bahkan mengelorakan pesan panggilan perjuangan kebudayaan, sebagai hakekat perjuangan nasional. Seperti dalam lirik, hiduplahtanahku, hiduplahnegeri, bangsaku, rakyatku, semuanya. Bangunlah jiwanya bangunlah badannya, untuk Indonesia Raya. Artinya perjuangan membangun Indonesia berarti membangun manusia seutuhnya dan masyarakat Indonesia seluruhnya.

Bait kedua memberikan deskripsi mengenai tanah air Indonesia, yaitu tanah air yang kaya. Bait ini mengungkapkan kesadaran sejarah, maka tanah air dinamakan tanah pusaka. Bait ini pula mengungkapkan sikap religius bangsa Indonesia yang mengajak berdoa kepada Tuhan Yang Maha esa. Selanjutnya dalam bait itu memberikan pesan bekerja membangun dalam pengertian suburlah tanahnya, suburlah jiwanya, bangsanya, rakyatnya, semuanya. Ini meminta adanya kesediaan dan kesetiaan bagi semua, yaitu sadarlah hatinya, sadarlah budinya.

Bait ketiga mengungkapkan tugas dan kewajiban bangsa sebagai puteraputeri tanah air. Tugas berarti menjaga mempertahankan, memajukan, yang intinya membangun secara menyeluruh secara berkesinambungan sebagai tugas abadi.

Bait ke empat yang selalu diulang-ulang sebagai refrein lagu menurut Muhamad Yamin adalah sebuah pesan klimaks sebagai pernyataan sumpah bakti pemuda yang bergelora dalam kongres pemuda tanggal 28 Oktober tahun 1928, yang berjanji teguh pada dasar kesatuan tanah air, bangsa, dan kebudayaan menuju kemerdekaan Indonesia yang berarti pernyataan tekad, kesediaan dan kesetiaan terhadap perjuangan membangun Indonesia yang merdeka dan bersatu, berdaulat, adil, dan makmur. Dengan gelora itu bangsa Indonesia bersatu dalam berjuang 
menyongsong masa depan bertujuan memperjuangkan derajat, martabat bangsa dan negara, serta masyarakat Indonesia (Murtopo, 1978: 76).

Lagu kebangsaan 'Indonesia Raya' diperdengarkan saat tertentu dan pada peristiwa penting saja dengan cara dan aturan tersendiri. Misalnya pada kesempatankesempatan di mana diperdengarkan lagu kebangsaan dengan alat musik, maka lagu itu dibunyikan lengkap satu kali, yaitu strofe dengan dua kali ulangan. Jika pada kesempatan-kesempatan lagu kebangsaan dinyanyikan lengkap satu bait, yaitu bait pertama dengan ulangan dua kali. Jika lagu kebangsaan dinyanyikan keseluruhan, yaitu tiga bait, maka sesudah bait pertama dan bait yang kedua dinyanyikan ulangan satu kali sesudah bait penghabisan dinyanyikan ulangan dua kali. Pada tahun 1951 dengan melibatkan 140 pemusik lagu kebangsaan 'Indonesia Raya' berkumandang diarransir dan diorkestrasi Jos Cleber, yang kemudian digubah dan direvisi kembali oleh R.A. Soedjasmin pimpinan Korp Musik Kepolisian Negara tahun 1952, dan berlaku saat ini. Fungsi utama lagu kebangsaan sebagai sarana upacara, di mana kedudukan pemain serta peserta upacara harus dilibatkan, hingga seni pertunjukan jenis ini bisa disebut Art of Participation (Soedarsono, 2001:170). Dengan memperlakukan sikap hormat pada lagu akhirnya diikuti segenap masyarakat Indonesia seperti organisasi politik, organisasi sosial, militer, organisasi sekolah sebagai upacara ritual bersifat nasional.

Dua kutub Pascakemerdekaan dan reformasi terdapat jurang pemisah setelah runtuhnya orde lama dan razim orde baru. Di era reformasi, konflik sosial akibat krisis politik, ekonomi, kebudayaan, dan mengarah disintegrasi bangsa menghancurkan arti kemerdekaan terkandung dalam teks lagu kebangsaan 'Indonesia Raya'. Akibat konflik lokal beberapa waktu lalu, seperti peristiwa Aceh, Poso, Maluku, Sampit, Papua, dan daerah lainnya meruntuhkan nilai persatuan bangsa yang digelorakan para pemuda 1928. Pengalaman sejarah yang gemilang kini seakan pudar ditelan masa. Peranan lagu kebangsaan 'Indonesia Raya' kini kurang dihargai, menjadi kegiatan seremonial bersifat slogan. Para elit politik kita belum menyadari dan menghayati makna yang terkandung dalam lagu, sementara para pendahulu berjuang mengorbankan darah, harta, air mata, dan jiwa raga.

Pernyataan di atas kini dapat dibuktikan dan berimbas pada dunia pendidikan. Dalam pelaksanaan upacara sekolah di seluruh pelosok tanah air, rata-rata para siswa kurang memiliki kesadaran kebangsaan, sehingga penganiayan, dan kekerasan terhadap sesama. Tawuran para pelajar dan mahasiswa serta masyarakat semakin meningkat. Para guru, dosen, ulama, dan tokoh masyarakat menganggap sesuatu hal biasa dan kurang mempedulikannya. Pergeseran nilai fungsi lagu maupun cara menyanyikan berimbas pula dalam upacara di lembaga pemerintah daerah sampai pemerintah pusat. Dewasa ini rata-rata peserta upacara tidak disiplin menghayati lagu, intonasi, maupun teks lagu kebangsaan, bahkan banyak yang belum hafal. Sementara pergeseran nilai fungsi nasionalisme dan persatuan makin lama makin memprihatinkan. Penyimpangan perilaku pejabat dan abdi negara, anggota DPR pusat maupun daerah serta masyarakat turut memperparah keadaan. Terjadi krisis moral seperti meningkatnya korupsi, sifat anarkis sekelompok masa menggunakan alasan agama sebagai sumber keuntungan, kendaraan politik, dan alat terorisme. Kasus narkoba dan fornografi, penebangan hutan dan pembalakan liar, penyelundupan kayu ilegal dan hasil bumi, perlindungan warga di luar negeri, tenaga kerja Indonesia, komersialisai penyalahgunaan pendidikan dan kesehatan masyarakat, melanggar HAM, bencana alam dan lingkungan serta transportasi di Indonesia yang terjadi berturut-turut adalah sebagai sebuah konspirasi politik yang menginginkan Indonesia dalam keadaan tidak stabil. Belum lagi, masalah konflik hak cipta kebudayaan serta wilayah perbatasan dengan negara tetangga akibat lemahnya pengawasan 
dan alutsista militer kita. Menghormati dan menghargai lagu kebangsaan mengajarkan agar bangsa selalu merenung dan intropeksi.

Konsep kebangsaan sebagai konsep nasional yang luhur tidak lepas dari nilainilai yang terkandung dalam budaya bangsa kita yang telah menjadi darah daging kehidupan. Sebagai sebuah harapan, tidak perlu bangsa Indonesia kini harus berpecahbelah, bercerai-berai, dan terkotak-kotak. Perjalanan api semangat lagu kebangsaan 'Indonesia Raya' berdasarkan Pancasila dan Undang-Undang Dasar 1945 bergelora dengan tidak memandang suku, ras, agama maupun golongan. Bangsa Indonesia harus membangun kembali harapan baru dan semangat baru serta pantang putus asa menciptakan persatuan demi menciptakan perdamaian abadi agar Indonesia adil makmur sejajar dengan bangsa-bangsa lain yang telah maju di segala bidang.

\section{SIMPULAN}

Dalam tiga dekade terakhir, mahasiswa mengalami pertumbuhan secara pesat dan mereka selalu berjuang sebagai oposisi melawan rezim yang berkuasa. Pada tahun 1966 gerakan mahasiswa berkobar di bawah panji "Tritura" utuk melawan Soekarno dan PKI. Gerakan itu telah menjadi legenda besar bagi Negara Republik Indonesia, karena mahasiswa beraliansi (ditunggangi) kekuatan militer berhasil menumbangkan Soekarno. Bagaimana pun mahasiswa mempunyai peran besar dalam melahirkan orde baru yang dipimpin oleh Jenderal Soeharto. Akan tetapi, ketika orde baru berdiri, mahasiswa terpaksa dipinggirkan dari arena politik oleh rezim Soeharto dengan dalih stabilitas politik dan pertumbuhan ekonomi. Mereka menentang dikotomi ekonomi antara sikaya dan simiskin, kekuasaan politik antara yang kuat dan yang lemah, reformasi belum mampu keluar dari konflik lokal yang berkepanjangan seperti alat perlawanan demokrasi yang kebablasan diluar ambang batas. Di masa peristiwa reformasi gerakan aksi mahasiswa Indonesia
Pada 12 Mei sampai dengan 17 Desember 1998 bahwa menyanyikan lagu-lagu perjuangan yang berfungsi sebagai alat perlawanan oposisi terhadap pemerintah akhir masa orde baru dalam menentang ketidakadilan dan demokrasi dan memberi inspirasi semangat perjuangan tempo dulu. Di Istana Merdeka, Soeharto tidak mampu mengendalikan kerusuhan, setelah gagal mendapatkan dukungan ulama, dan tokoh masyarakat ditambah 14 orang menterinya mengundurkan diri. Akhirnya, Soeharto mundur dari jabatan presiden digantikan BJ. Habibie, dengan menyanyikan lagu kebangsaan 'Indonesia Raya'. Ketika itu mahasiswa berhasil dalam perjuangan reformasi. Walaupun demokrasi yang kebablasan dan konflik antar-etnis ada sebagian yang dapat diselesaikan di antaranya konflik Aceh, Poso, Maluku, korupsi dan anggaran pendidikan; namun di sisi lain muncul konflik baru yang harus mendapat prioritas penyelesaian serta solusinya adalah penegakan hukum dan hak azazi manusia.

Fungsi lagu kebangsaan 'Indonesia Raya' selama tiga perempat abad telah berjuang mempersatukan bangsa di dalam prosesnya melalui tiga tahap sebagai berikut: Pertama, Masa sumpah pemuda 28 Oktober 1928 adalah menghimpun rasa kebangsaan merupakan kesadaran berbangsa yang tumbuh secara alami dalam diri setiap orang karena kebersamaan sosial yang tumbuh dari kebudayaan, sejarah, dan aspirasi perjuangan harus tetap dilestarikan hingga saat ini sebagai jiwa nasionalisme. Kedua, Masa kolonialisme dan pendudukan Jepang adalah aspirasi semangat kebangsaan dan tekad sejati seluruh masyarakat Indonesia untuk membela dan berkorban bagi kepentingan bangsa dan negara, sebagai warisan jiwa patriotik yang harus tetap dipelihara segenap bangsa Indonesia saat ini guna membela kedaulatan negara bila ada ancaman dari dalam maupun dari luar. Ketiga, Dalam mengisi kemerdekaan terjadi proses dinamika politik sejak orde lama, orde baru, dan reformasi saat ini, yaitu implementasi 
rasa, semangat, dan paham kebangsaan, pikiran-pikiran nasional tentang hakekat, cita-cita kehidupan, dan perjuangan masa lalu. Penghayatan wawasan kebangsaan tidakcukup mempelajari paham kebangsaan, bahkan harus dibuktikan dan digali lebih dalam sampai rasa kebangsaan itu tumbuh di dalam hati rakyat. Akhirnya dengan cara ini semangat kebangsaan akan dapat dikobarkan dan dihayati dalam pikiran, perilaku rakyat Indonesia agar tetap bersatu padu merupakan salah satu aspek yang diperjuangkan W.R. Supratman tergambar dalam arti dan makna lagu Kebangsaan 'Indonesia Raya'.

\section{DAFTAR PUSTAKA}

Dewantara, K. H., 1948, Kebudayaan. Yogyakarta: Taman Siswa.

Dibdin, J. C., 1962, "Nationality in Music", dalam Roman Rolland, ed., International Library of Music for Home and Music Litertur 2, New York: The University Sosiety.

Djohan, 2008, Musik Revolusi Indonesia, resensi buku Karya Wisnu Mintargo dalam Jurnal Ke'teg' Vol. 8 No. 1 ISI Surakarta.

Dungga, J.A. dan L. Manik, 1952, Musik di Indonesia dan Persoalannya, Jakarta:Balai Pustaka.

Ganap. V., 2008, Sumbangsih Ilmu Pengetahuan Musik Dalam Pembentukan Jati diri Bangsa, Pidato Pengukuhan Jabatan Guru Besar Pada Fakultas Seni Pertunjukan. ISI Yogyakarta, tanggal 9 Januari.

Garna, Y. K., 1996, Ilmu-ilmu Sosial dasar, Kasus, Konsepsi, Posisi. Bandung: Progran Pascasarjana Universitas Padjadjaran.

Kamajaya, 1979, Sejarah Bagimu Neg'ri Lagu Nasional, Yogyakarta: U.P. Indonesia.

Kuntowijoyo, 1994, Metodologi Sejarah, Yogyakarta: Tiara Wacana.

Marbun. B.N, 1996, Kamus Politik, Jakarta: Pustaka Sinar Harapan.
Mintargo, W., 2001, Fungsi Lagu Perjuangan Dalam Konteks Kemerdekaan tahun 1945-1949, Tesis, Yogyakarta: Universitas Gadjah Mada.

2003, Lagu Propaganda dalam Revolusi Indonesia: 1945-19449, dalam Jurnal Humaniora Volume XV, No. 1/2003. Yogyakarta: Fakultas Ilmu Budaya UGM.

,2008, Musik Revolusi Indonesi, Yogyakarta: Penerbit Ombak.

Murtopo, A., Strategi Kebudayaa, Jakarta: Yayasan Proklamasi.

More, F. H.,1988, Hubungan Masyarakat, Prinsif, Kasus, dan Masalah, terj. Suwiryo, Bandung:Roesdakarya.

Nurzain, U., 1981, Namaku Wage, Jakarta: Pustaka Sinar Harapan.

Pranarka, A.M.W, 1986, Wawasan Kebangsaan, Ketahanan Nasional dan Wawasan Nusantara, Yogyakarta: Lembaga Pengkajian Kebudayaan Sarjana Wiyata Taman Siswa.

Sudirdjo, R. U., 1976, Lima Tahun Perang Kemerdekaan 1945-1949, Jakarta: Penerbit Alda, 1976.

Sularto, B., 1982, Lagu Kebangsaan Indonesia Raya, Jakarta: Direktorat Jenderal Kebudayaan DEPDIKBUD.

Sumaryono. E, 1996, Hermeunetik Sebuah Metode Filsafat, Yogyakarta: Kanisius.

Sutrisno, K dan Safwan. M., 1978, Pahlaan Nasional W.R. Supratman. Jakarta: Mutiara.

Soebagijo I.N, 1985, Tragedi Kehidupan Seorang Komponis, Biografi W.R. Supratman, Jakarta: Intidayu Press.

Soedargo, 1950, Pemandangan Dalam Negara dalam Majalah Mimbar Indonesia, edisi I, Jakarta 7 Januari.

Soedarsono, R.M, 2001, Metode Penelitian Seni Pertunjukan Dan Seni Rupa. Bandung: Masyarakat Seni Pertunjukan Indonesia. 
Soeharto, 1982, Saksi Sejarah Mengikuti Soesilo, Y. Edi, 1996, Sejarah Lagu Kebangsaan Pergerakan Dwitunggal, Jakarta:P.T. Indonesia Raya, Tesis Guna Mencapai Gunung Agung. $\quad$ Derajad S-2 Universitas Gadjah Mada. 